\title{
Composição Corporal e Exigências Nutricionais de Energia e Proteína para Cordeiros em Crescimento
}

\author{
Cleber Cassol Pires², Lisiane Furtado da Silva ${ }^{3}$, Luis Maria Bonnecarrère Sanchez ${ }^{2}$
}

\begin{abstract}
RESUMO - Este trabalho foi realizado com o objetivo de determinar a composição corporal para gordura, proteína e cinzas, as exigências líquidas de energia e proteína para ganho de peso e as exigências de proteína metabolizável de cordeiros em crescimento. Foram utilizados 22 cordeiros machos inteiros, filhos de carneiros Texel e ovelhas cruzas (Texel x Ideal); destes, quatro foram abatidos no início do experimento (24 horas após o nascimento) e grupos de seis cordeiros, ao desmame, aos 28 e $33 \mathrm{~kg}$ de peso vivo. As equações de predição da composição corporal de proteína, gordura, cinzas e energia foram realizadas de acordo com o ARC (1980), por intermédio da regressão do logaritmo de proteína, gordura, cinzas e energia no corpo vazio, em relação ao logaritmo do peso de corpo vazio (PCV). As exigências líquidas de proteína e energia para ganho de peso foram obtidas por meio das equações de predição da composição corporal, ao passo que as exigências de proteína metabolizável foram estimadas de acordo com o AFRC (1993). Os conteúdos corporais de proteína, gordura, energia e matéria mineral para cordeiros de 5 a $30 \mathrm{~kg}$ PCV variaram de 141,69 a 186,24 g/kg PCV; 24,49 a 158,11 g/kg PCV; 1088,75 a 2451,55 kcal/kg PCV; e 27,55 a 33,70 g/kg PCV, respectivamente. As estimativas das exigências líquidas para ganho foram: energia, 399,93 e $892,21 \mathrm{kcal} / 250 \mathrm{~g}$ de ganho, e proteína de 40,98 e 53,70 g/250g de ganho, para cordeiros de 5 e $30 \mathrm{~kg}$ de PCV, respectivamente. As exigências de proteína metabolizável para animais de 5 e $30 \mathrm{~kg}$ de peso vivo foram de 79,09 a 121,13 g/250g de ganho.
\end{abstract}

Palavras-chave: composição corporal, exigência líquida, ganho de peso, ovino

\section{Corporal Composition and Nutritional Requirements for Energy and Protein of Growing Lambs}

\begin{abstract}
This work was conducted with the objective to determine the body composition for fat, protein and ash, the net requirements of energy and protein for weight gain, and the requirements of metabolizable protein of growing lambs. Twenty-two male lambs, sired by Texel males, from crossbreed Texel x Ideal dams were used. Four lambs were slaughtered at the beginning of the experiment ( 24 hours after birth) and groups of six lambs were slaughtered at weaning, at 28 and $33 \mathrm{~kg}$ of live weight. The prediction equations of the corporal composition of protein, fat, ash and energy were fitted, according to the ARC (1980), by the regression of log of fat, protein, ash and energy, content in the empty body, in relation to the log of empty body weight (EBW). The net requirements of protein and energy for weight gain were obtained based on the prediction equations of body composition, while of metabolizable protein requirements were estimated in agreement with the AFRC (1993). The body contents of protein, fat, energy and ash for lambs from 5 to $30 \mathrm{~kg}$ EBW. ranged from 141.69 to $186.24 \mathrm{~g} / \mathrm{kg}$ EBW; 24.49 to $158.11 \mathrm{~g} / \mathrm{kg} \mathrm{EBW} ; 1088.75$ to $2451.55 \mathrm{Kcal} / \mathrm{kg} \mathrm{EBW}$, and 27.55 to $33.70 \mathrm{~g} / \mathrm{kg}$ EBW, respectively. The estimated net requirements for weight gain were: energy, from 399.93 to $892.21 \mathrm{kcal} / 250 \mathrm{~g}$ of gain, and protein from 40.98 to $53.70 \mathrm{~g} / 250 \mathrm{~g}$ of gain, for lambs from 5 to $30 \mathrm{~kg}$ of EBW, respectively. The requirements of metabolizable protein for animals from 5 to $30 \mathrm{~kg}$ live weight ranged from 79.09 to $121.13 \mathrm{~g} / 250 \mathrm{~g}$ of gain.
\end{abstract}

Key Words: corporal composition, net requirement, sheep, weight gain

\section{Introdução}

A composição corporal e do ganho de peso estão intimamente relacionadas, sendo a composição corporal conseqüência da composição do ganho. Outros fatores como estado de desenvolvimento do animal, sexo, raça e nutrição também influem na composição corporal e do ganho.

De acordo com o AGRICULTURAL
RESEARCH COUNCIL - ARC (1980), a composição corporal de ovinos, durante o crescimento, varia com a raça e o sexo. Comparando animais da raça Merino com outros genótipos (machos inteiros, castrados e fêmeas), este comitê determinou, em termos de composição de proteína, que os tipos raciais são similares, existindo diferença entre sexos, uma vez que machos castrados e inteiros possuem maior conteúdo protéico que fêmeas. Quanto à gordura, existe

\footnotetext{
${ }^{1}$ Parte da Dissertação apresentada pelo segundo autor à Universidade Federal de Santa Maria para obtenção do título de Mestre em Zootecnia. ${ }^{2}$ Professor do Departamento de Zootecnia da UFSM - E.mail:cpires@ccr.ufsm.br

3 Zootecnista, Mestre.
} 
diferença entre raças e sexos, decrescendo na seguinte ordem: machos Merino castrados, fêmeas, machos castrados e machos inteiros, de outros genótipos, enquanto o conteúdo mineral permanece constante em $31 \mathrm{~g} / \mathrm{kg}$ de peso de corpo vazio.

A composição corporal, por $\mathrm{kg}$ de peso de corpo vazio, de cordeiros abatidos na fase de crescimento varia de 0,216 a $0,270 \mathrm{~kg}$ para gordura; 0,100 a $0,160 \mathrm{~kg}$ para proteína; 7,94 a 14 MJ para energia; e 0,45 a 0,59 kg para água ( SEARLE, et al., 1979; SAMPELAYO et al., 1993; e WILKINSON e GREENHALGH, 1995). Para taxas de ganho de 50 a 300 g/dia, a composição do ganho varia, para proteína; de 164 a 160 (g/kg); gordura, de 70 a 153 (g/kg); e energia, de 6,3 a 9,6 (MJ/kg), de acordo com ARC (1980).

No Brasil, CARVALHO (1980) verificou que, para o conjunto de cordeiros (cruzas Texel x Ideal) castrados, não-castrados e fêmeas, abatidos aos 100 dias de idade, a composição corporal $(\mathrm{g} / \mathrm{kg}$ de peso corporal vazio) para gordura se elevou de 44,74 a 299,10 e para proteína, de 149,64 a 189,74, respectivamente, para os pesos de corpo vazio de 5 e $30 \mathrm{~kg}$. $\mathrm{O}$ conteúdo de gordura do ganho de peso $(\mathrm{g} / \mathrm{kg}$ de ganho de peso corporal vazio) foi de 92,10 e 505,52, para os mesmos pesos supracitados.

A concentração de cinzas, de acordo com o ARC (1980), em geral, varia menos que a de gordura e proteína, sendo que um cordeiro com $5 \mathrm{~kg}$ de peso vivo (PV) ao nascimento apresenta valores de $40 \mathrm{~g} / \mathrm{kg}$ de PV.

O conhecimento das exigências nutricionais de ovinos, sob condições brasileiras, é necessário para a elaboração de dietas mais eficientes e econômicas, uma vez que, até o momento, são utilizados dados internacionais para cálculos de rações; além disso, a demanda de nutrientes varia com o clima, a raça e o estado fisiológico, entre outros fatores. Os estudos para determinação das exigências nutricionais de ovinos são recentes no Brasil, porém de grande importância, uma vez que a nutrição é um dos principais pilares num sistema produtivo.

A exigência de energia para ganho significa a quantidade que deve ser fornecida ao animal, para existir aumento no peso corporal. Segundo o NATIONAL RESEARCH COUNCIL - NRC (1996), para bovinos de corte, as exigências de energia podem ser influenciadas por peso corporal, genótipo, sexo, idade, estação do ano, temperatura, estado fisiológico e histórico nutricional. RATTRAY (1973), trabalhando com ovinos de 3 a 5 meses de idade, encontrou, para energia líquida de mantença
(Elm), valores variando de 890 a $1495 \mathrm{kcal} / \mathrm{dia}$ e, para ganho de $0,200 \mathrm{~kg} / \mathrm{dia}$, de 720 a $1210 \mathrm{kcal}$ ELg/dia. Segundo o ARC (1980), para ganho de peso, são recomendados valores de 1,482 a 2,031 Mcal EM/100g de ganho de PV para machos inteiros de 20 a $30 \mathrm{~kg}$ PV (com gasto para atividade de 2,53 Mcal/kg PV/dia). O NRC (1985) sugere, para cordeiros de média maturidade com pesos vivos de 10 a $35 \mathrm{~kg}$, valores de 155 a $397 \mathrm{kcal}$ ELg/ $100 \mathrm{~g}$ de ganho. O AGRICULTURAL AND FOOD RESEARCH COUNCIL - AFRC (1993) recomenda para cordeiros machos inteiros de $20 \mathrm{~kg}$ e $30 \mathrm{~kg}$ valores de 1,386 e 1,936 Mcal EM/100g de ganho, respectivamente.

No Brasil, CARVALHO (1998) determinou para cordeiros inteiros, com 5, 15 e $30 \mathrm{~kg}$ de PV, exigências líquidas de energia de 0,326;0,565; e 0,817 Mcal/ 200 g de ganho, respectivamente. SOUSA (1998b), trabalhando com caprinos em crescimento, com pesos vivos de 18,22 e $26 \mathrm{~kg}$, verificou valores de energia líquida de 0,270;0,256; e 0,245 Mcal/150g, respectivamente.

Segundo ARMSTRONG (1995), os requerimentos líquidos de proteína para mantença deverão atender o $\mathrm{N}$ basal endógeno requerido, juntamente com as perdas de proteína na forma de pêlos, escamação da pele etc. Já a proteína para ganho de peso é aquela que fica retida no organismo animal.

De acordo com a metodologia sugerida pelo NRC (1985), a proteína depositada no ganho de cordeiros de média maturidade, com 0,200 kg de ganho/dia, é de 44,$49 ; 38,25 ; 35,43$; e 32,78 g para cordeiros com 10 , 20, 25 e $30 \mathrm{~kg}$, respectivamente. O AFRC (1993) recomenda $95 \mathrm{~g}$ proteína metabolizável $(\mathrm{PM}) / 200 \mathrm{~g}$ de ganho para cordeiros de $20 \mathrm{~kg}$; e $100 \mathrm{~g} \mathrm{PM} / 200 \mathrm{~g}$ de ganho para animais de $30 \mathrm{~kg}$. Já para ganhos de $0,250 \mathrm{~kg}$, a recomendação é 110 e 114 g PM para cordeiros de 20 e $30 \mathrm{~kg}$, respectivamente.

No Brasil, CARVALHO (1998), trabalhando com cordeiros, determinou valores de exigências líquidas de proteína de 32,27; 34,48; e 36,04 g/250 g de ganho para machos inteiros de 5,15 e $30 \mathrm{~kg}$ PV, respectivamente. As exigências de proteína metabolizável para os mesmos pesos foram de 65,11; 78,87; e 93,58 g/ $250 \mathrm{~g}$ de ganho, respectivamente.

Este trabalho foi conduzido para determinar a composição corporal e do ganho em proteína, extrato etéreo, energia e minerais, as exigências líquidas de energia e proteína para ganho de peso e as exigências de proteína metabolizável para cordeiros 3/4 Texel + 1/4 Ideal em crescimento. 


\section{Material e Métodos}

O experimento foi conduzido no Setor de Ovinocultura, do Departamento de Zootecnia da Universidade Federal de Santa Maria (UFSM), no período de julho a dezembro de 1997 . Foram utilizados 22 cordeiros machos inteiros, filhos de carneiros Texel e ovelhas cruzas (Texel x Ideal),. distribuídos aleatóriamente nos tratamentos: T1 - abate ao nascer, T2 - abate ao desmame (45 dias de idade), T3 abate aos $28 \mathrm{~kg}$ de peso vivo (PV) e T4 - abate aos $33 \mathrm{~kg}$ de PV.

Do total de cordeiros utilizados, quatro foram abatidos ao nascimento (abate inicial) e 18 foram confinados com suas respectivas mães em baias individuais, com área de $4 \mathrm{~m}^{2}$, até o momento de serem desmamados (45 dias de idade). Nessa ocasião, foram abatidos seis animais, e os doze restantes, quando atingiram $28 \mathrm{~kg}$ (seis animais) e $33 \mathrm{~kg}$ (seis animais) de PV.

Durante o período experimental, foram utilizadas duas dietas, sendo a primeira do nascimento ao desmame, balanceada para atender as exigências nutricionais da ovelha lactante e a segunda, para os cordeiros desmamados. Ambas as dietas foram calculadas de acordo com NRC (1985).

Após o abate de cada animal, foram pesados sangue, pele, patas, cabeça, fígado, pulmão + traquéia, coração, gordura do coração, rins, gordura perirenal, gordura marrom (no caso dos recém-nascidos), esôfago, língua, timo, baço, diafragma, bexiga, aparelho reprodutor (pênis e testículos), gordura associada ao aparelho reprodutor e gordura associada ao trato gastrintestinal. O rúmen, retículo, omaso e abomaso, intestino grosso e delgado foram pesados cheios e vazios, após lavagem e escorrimento da água.

Os órgãos internos, trato gastrintestinal (TGI) e depósitos de gordura interna, foram totalmente moídos em máquina manual de moer carne, e constituíram as amostras: 1 - órgãos internos (pulmão + traquéia, coração, rins, esôfago, língua, timo, baço, diafragma, bexiga, fígado e aparelho reprodutor); 2 aparelho digestivo (rúmen, retículo, omaso, abomaso, intestino grosso e intestino delgado); 3 - gordura interna (gordura do coração, dos rins, do aparelho reprodutor e do TGI), no caso dos recém-nascidos, esta última amostra foi constituída pela gordura marrom; 4 - pele (amostra retirada da região central de tamanho e peso conhecido) e 5 - sangue (o total coletado constituiu a própria amostra).

A carcaça foi resfriada em câmara frigorífica por
24 horas a $2{ }^{\circ} \mathrm{C}$ e, posteriormente, obtido o peso de carcaça fria (PCF). Após resfriamento, foi dividida ao meio e, no lado direito, realizou-se a separação do pescoço, da costela, paleta, do quarto e espinhaço, os quais foram pesados separadamente. Cada corte da meia-carcaça foi dissecado e as quantidades de osso, músculo e gordura, pesadas e, posteriormente, amostradas (amostras 6, 7 e 8), por intermédio de alíquotas ( $10 \%$ de cada componente). Na seqüência, estas amostras foram moídas em máquinas de moer carne, sendo as amostras de osso previamente cortadas em pedaços pequenos em serra de fita.

As amostras moídas foram colocadas em bekers de vidro, com capacidade para $250 \mathrm{~mL}$ e levados à estufa a $105^{\circ} \mathrm{C}$, para determinação da matéria seca; na sequiência, procedeu-se ao pré-desengorduramento, conforme metodologia de KOCH e PRESTON (1979).

As amostras de sangue foram colocadas em bandejas de alumínio e levadas à estufa com circulação forçada de ar, por 72 horas a $55^{\circ} \mathrm{C}$, para determinação da percentagem de matéria seca parcial.

Todas as amostras, após pré-desengorduramento, foram moídas em liqüidificador industrial e, na seqüência, foram realizadas as determinações de proteína bruta $(\mathrm{PB})$, pelo método de micro Kjeldahl; extrato etéreo (EE), em aparelho soxhlet; e matéria mineral $(\mathrm{MM})$, em forno mufla a $600^{\circ} \mathrm{C}$, conforme metodologia descrita por SILVA (1990).

As quantidades de gordura, proteína e cinzas no corpo de cada animal foram obtidas a partir do somatório das quantidades encontradas em cada amostra. O conteúdo corporal de energia bruta (EB) foi estimado multiplicando-se as quantidades de $\mathrm{PB} e$ EE totais do corpo do animal pelos seus equivalentes calóricos (5,6 e 9,40 kcal/g, respectivamente), segundo o ARC (1980).

A predição da composição corporal foi determinada por intermédio das equações de regressão das quantidades de PB, EE, MM e EB no corpo vazio, em função do logaritmo do peso de corpo vazio (PCV), conforme o ARC (1980).

Para transformação de peso vivo (PV) em PCV, utilizou-se a equação de regressão do PCV dos 22 animais do presente trabalho, em função do PV e da idade ao abate dos mesmos.

Com base nas equações de predição da composição corporal, foi determinada, para PB, EE, MM e $\mathrm{EB}$, a composição do ganho para os intervalos de pesos estudados. Por exemplo, encontrou-se a composição do ganho de um animal de $20 \mathrm{~kg}$ por intermédio da diferença entre a composição corporal de um 
animal pesando $19,5 \mathrm{~kg}$ e outro com $20,5 \mathrm{~kg}$.

Foram estimadas as exigências líquidas de ganho para EB e PB, por meio das equações de regressão determinadas para conteúdo corporal (Tabela 1). As exigências líquidas para PB e EB foram calculadas para diferentes ganhos de peso e distintos pesos, conforme o ARC (1980). Por exemplo, calculou-se o conteúdo corporal em proteína de um animal pesando $20 \mathrm{~kg}$ e outro pesando $20,25 \mathrm{~kg}$; a diferença encontrada entre os valores é a exigência líquida de proteína para o ganho de $250 \mathrm{~g}$ de um cordeiro pesando $20 \mathrm{~kg}$.

As exigências de proteína metabolizável para ganho de peso foram estimadas conforme AFRC (1993).

As análises estatísticas foram realizadas utilizando-se o pacote estatístico SAS (SAS, 1990).

\section{Resultados e Discussão}

As equações de predição do peso do corpo vazio (PCV), em função do peso vivo (PV) e da idade (Id.), e as equações de predição da composição corporal, em termos de PB, EE, MM e EB, são apresentadas na Tabela 1. Por intermédio destas equações, estimaramse os conteúdos corporais/kg de PCV (Tabela 2).

Observa-se que houve aumento no conteúdo corporal em proteína, à medida que se elevou o PCV. Estes resultados discordam daqueles apresentados pelo ARC (1980), em que o conteúdo protéico diminui quando se eleva o PCV. Este comitê refere-se a valores de $175 \mathrm{~g} / \mathrm{kg} \mathrm{PV}$, para cordeiros recém-nascidos, e 178 e $156 \mathrm{~g} / \mathrm{kg}$, para animais com 10 e $35 \mathrm{~kg}$ de PCV. Por outro lado, os resultados assemelham-se sos encontrados por SEARLE et al. (1979), os quais observaram conteúdo corporal de 0,100 e $0,160 \mathrm{~kg}$ de PB/kg de PCV, respectivamente, para cordeiros com intervalo de peso de 14 a $18 \mathrm{~kg}$ de PV e 18 a $23 \mathrm{~kg}$ de PV.

$\mathrm{O}$ conteúdo corporal em gordura apresentado pelos cordeiros, nesta pesquisa, foi, em média, $7,75 \%$ inferior àquele citados pelo ARC (1980), que apresenta valores de 56, 84, 111, 139 e $166 \mathrm{~g} / \mathrm{kg}$, para PCV de 10, 15, 20, 25 e $30 \mathrm{~kg}$, respectivamente. Também foi inferior aos encontrado por SEARLE et al. (1979), que verificaram, em animais com PV de 14 a $23 \mathrm{~kg}$, conteúdo corporal de gordura variando de 240 a $270 \mathrm{~g} / \mathrm{kg}$ de PCV. WILKINSON e GREENHALGH (1995) verificaram que animais com PCV de $43,45 \mathrm{~kg}$ apresentaram $215,6 \mathrm{~g}$ de gordura/kg de PCV e aqueles pesando $36,57 \mathrm{~kg}, 178,5 \mathrm{~g}$ de gordura/ $\mathrm{kg}$ de $\mathrm{PCV}$.

CARVALHO (1998), trabalhando em condições semelhantes às deste trabalho, encontrou para gordura resultados, em média, $86,17 \%$ superiores: 44,74 ; 93,$13 ; 143,07 ; 193,98 ; 245,63$; e 297,89 g para os respectivos PCV de 5, 10, 15, 20, 25 e 30. Provavelmente, estas diferenças devam-se ao fato de os cordeiros, utilizados no presente trabalho, terem maior definição genética da raça Texel, cujos animais depositam menos gordura que os de outras raças.

$\mathrm{O}$ conteúdo corporal de energia aumentou à medida que o PCV dos cordeiros se elevou, o que está de acordo com o ARC (1980). Os valores de energia, encontrados nesse experimento, foram inferiores aos apresentados pelo ARC (1980), para PCV de 10 e $15 \mathrm{~kg}$, porém superiores aos de 20 e $25 \mathrm{~kg}$ de $\mathrm{PCV}$ e iguais aos apresentados para PCV de $30 \mathrm{~kg}$. Foram inferiores também aos encontrados por SEARLE et al. (1979), que verificaram valores de 2,868 e 3,346 Mcal EB/kg de PCV, para animais de 14 a $18 \mathrm{~kg}$ PV e de 18 a $23 \mathrm{~kg}$ $\mathrm{PV}$, respectivamente. SAMPELAYO et al. (1993)

Tabela 1 - Regressão para o peso de corpo vazio (PCV), em função do peso vivo (PV) e da idade (Id.), e para as quantidades de proteína bruta (PB), extrato etéreo (EE), energia bruta (EB) e minerais (MM) presentes no corpo vazio, em função do logaritmo do PCV

Table 1 - Regression of the empty body weight (EBW), on live weight $(L W)$ and age $(A)$, and for the amounts of crude protein $(C P)$, ether extract $(E E)$, gross energy $(G E)$ and minerals $(M M)$ present in the empty body on the EBW logharitm

\begin{tabular}{llc}
\hline Item & \multicolumn{1}{c}{$\begin{array}{c}\text { Regressão } \\
\text { Regression }\end{array}$} & $\mathrm{r}^{2}$ \\
\hline $\begin{array}{l}\text { Peso }(\mathrm{kg}) \\
\text { Weight }\end{array}$ & $\operatorname{PCV}(E B W)=0,211688+0,977391 \mathrm{PV}(L W)-0,028676 \operatorname{Id}(A)$ & 99,63 \\
$\mathrm{~PB}(\mathrm{~g})$ & $\operatorname{Lôg} \mathrm{PB}(C P)=2,044687+1,152594 \operatorname{Lôg~PCV}(E B W)$ & 99,16 \\
$C P$ & $\operatorname{Lôg} \mathrm{EE}=0,661581+2,040790 \operatorname{Lôg} \operatorname{PCV}(E B W)$ & 95,19 \\
$\mathrm{EE}, \mathrm{g}$ & $\operatorname{Lôg} \operatorname{EB}(G E)=-0,279715+1,453014 \operatorname{Lôg} \operatorname{PCV}(E B W)$ & 97,53 \\
$\mathrm{~EB}(\mathrm{kcal} / \mathrm{kg})$ & $\operatorname{Lôg} \mathrm{MM}(A S)=1,361401+1,112562 \operatorname{Lôg} \operatorname{PCV}(E B W)$ & 95,00 \\
$G E$ & & \\
$\mathrm{MM}, \mathrm{g}$ & &
\end{tabular}


observaram, para cordeiros com 2, 30 e 60 dias de idade, conteúdo energético de 1,$027 ; 1,613$; e $1,898 \mathrm{Mcal} / \mathrm{kg}$ de PCV, respectivamente. Trabalhando com cordeiros em crescimento, CARVALHO (1998) encontrou valores de 1,32 a 3,58 Mcal de EB/ $\mathrm{kg}$ de PCV, para animais com 5 a $30 \mathrm{~kg}$ de PCV, em média $33,62 \%$ superiores aos desta pesquisa.

Os resultados apresentados para conteúdo de minerais indicam aumento dos 5 aos $20 \mathrm{~kg} \mathrm{PCV}$; a partir deste, mantêm-se constante, o que está de acordo com o ARC (1980), que relata a estabilização ao redor de $31 \mathrm{~g} / \mathrm{kg}$. WILKINSON e GREENHALGH (1995) determinaram, para ovinos com PCV de 36,57 e $43,45 \mathrm{~kg}$, valores de 32,1 e $29,1 \mathrm{~g}$ de $\mathrm{MM} / \mathrm{kg}$, respectivamente.

As estimativas das quantidades dos nutrientes depositados por kg de ganho em PCV, nas diferentes faixas de pesos, obtidas pelas equações contidas na Tabela 1, são apresentadas na Tabela 3. Constam da Tabela 4 as quantidades de nutrientes, depositadas por kg de ganho em PV, que foram estimadas a partir das mesmas equações, fazendo-se a conversão de PV para PCV.

Os resultados encontrados para o aumento do conteúdo de PB no ganho de PCV, de 163,28 a $214,66 \mathrm{~g} / \mathrm{kg}$ de PCV (Tabela 3), diferem daqueles do ARC (1980), os quais decrescem de 159 a $142 \mathrm{~g} / \mathrm{kg}$ de ganho de PCV, para cordeiros de 10 a $30 \mathrm{~kg}$ de PCV. Por outro lado, são próximos aos encontrados para caprinos (RESENDE, 1989 e SOUSA, 1998a) e ovinos (CARVALHO, 1998). Os resultados obtidos estão de acordo com os apresentados pelo ARC (1980), no que se refere ao aumento do conteúdo de gordura e energia do ganho, em consequiência da elevação do PCV. De acordo com o ARC (1980), o conteúdo de gordura por $\mathrm{kg}$ de ganho de PCV varia de 111 a 330 g, para PCV de 10 e $30 \mathrm{~kg}$. Em relação ao conteúdo energético do ganho, os valores apresentados por esse comitê são inferiores aos encontrados nesta pesquisa, para PCV de 10,15 e $20 \mathrm{~kg}$, mas são superiores para PCV de 25 e $30 \mathrm{~kg}$.

$\mathrm{O}$ aumento do conteúdo de gordura e energia no ganho em PCV e PV, em decorrência de maiores pesos, concorda, em termos de tendência, mas não em valores, com os de CARVALHO (1998), que obteve valores de 92,10 e 613,08 g de EE/kg de ganho de PCV, para cordeiros de 5 e $30 \mathrm{~kg}$. Estes valores, no entanto, foram $87,12 \%$ superiores aos encontra-

Tabela 2 - Conteúdos corporais de proteína bruta (PB), extrato etéreo (EE), energia bruta (EB) e minerais (MM), no peso de corpo vazio

Table 2 - Body contents of crude protein (CP), ether extract (EE), gross energy (GE) and minerals (MM) in the empty body weight

\begin{tabular}{lrrrrrr}
\hline Item & \multicolumn{5}{c}{$\begin{array}{c}\text { Peso de corpo vazio }(\mathrm{kg}) \\
\text { Empty bodyweight }\end{array}$} \\
\cline { 2 - 7 } & \multicolumn{1}{c}{5} & \multicolumn{1}{c}{10} & \multicolumn{1}{c}{15} & \multicolumn{1}{c}{20} & \multicolumn{1}{c}{25} & 30 \\
\hline PB $(C P), \mathrm{g}$ & 141,69 & 157,50 & 167,55 & 175,07 & 181,13 & 186,24 \\
EE, g & 24,49 & 50,39 & 76,85 & 103,68 & 130,78 & 158,11 \\
EB $(G E), \mathrm{kcal} / \mathrm{kg}$ & 1088,75 & 1490,39 & 1790,90 & 2040,19 & 2257,21 & 2451,55 \\
MM, g & 27,55 & 29,78 & 31,17 & 32,20 & 33,02 & 33,70 \\
\hline
\end{tabular}

Tabela 3 - Conteúdo de proteína bruta (PB), extrato etéreo (EE), energia bruta (EB) e matéria mineral (MM), por kg de peso de corpo vazio (PCV) de cordeiros em crescimento

Table 3 - Body contents of crude protein (CP), ether extract (EE), gross energy (GE) and minerals (MM), per kg of empty body weight (EBW) of growing lambs

\begin{tabular}{lrrrrrr}
\hline Item & \multicolumn{7}{c}{ PCV $(\mathrm{kg})$} \\
& \multicolumn{1}{c}{5} & \multicolumn{1}{c}{ 10 } & \multicolumn{1}{c}{15} & \multicolumn{1}{c}{20} & \multicolumn{1}{c}{25} & \multicolumn{1}{c}{30} \\
\hline & 163,28 & 181,52 & 193,11 & 201,78 & 208,77 & 214,66 \\
PB $(C P), \mathrm{g}$ & 49,99 & 102,84 & 156,84 & 211,58 & 266,90 & 322,66 \\
EE, g & 1581,31 & 2165,33 & 2602,08 & 2964,34 & 3279,70 & 3562,10 \\
EB $(G E), \mathrm{kcal} / \mathrm{kg}$ & 30,64 & 33,13 & 34,68 & 35,82 & 36,73 & 37,50 \\
MM, g & & & & & &
\end{tabular}


PIRES et al.

Tabela 4 -Conteúdo de proteína bruta $(\mathrm{PB})$,extrato etéreo $(E E)$, energia bruta $(E B)$ e matéria mineral (MM), por kg de ganho de peso vivo (PV), de cordeiros em crescimento Table 4 - Body contents of crude protein (CP), ether extract (EE), gross energy (GE) and minerals $(M M)$, per $\mathrm{kg}$ of live weight (LW) of growing lambs

\begin{tabular}{lrrrrrr}
\hline Item & \multicolumn{7}{c}{$\mathrm{PV}(\mathrm{kg})$} \\
& \multicolumn{1}{c}{5} & \multicolumn{1}{c}{10} & \multicolumn{1}{c}{15} & \multicolumn{1}{c}{20} & \multicolumn{1}{c}{25} & \multicolumn{1}{c}{30} \\
\cline { 2 - 7 } & 150,55 & 160,80 & 164,88 & 177,54 & 177,33 & 175,74 \\
PB $(C P), \mathrm{g}$ & 46,66 & 87,84 & 126,04 & 172,61 & 207,11 & 237,12 \\
EE, g & 1464,16 & 1894,60 & 2176,58 & 2542,40 & 2701,92 & 2811,63 \\
EB $(G E), \mathrm{kcal} / \mathrm{kg}$ & 28,25 & 29,40 & 29,69 & 31,63 & 31,33 & 30,85 \\
MM, g & & & & & & \\
\hline
\end{tabular}

dos no presente trabalho. Tendência inversa foi constatada para caprinos (SOUSA ,1998 a).

O ganho de peso médio verificado para os cordeiros abatidos com $28,3 \mathrm{~kg}$ foi de $0,254 \mathrm{~kg}$ e para os abatidos com $32,57 \mathrm{~kg}$, de $0,237 \mathrm{~kg}$; portanto, as exigências líquidas de energia e proteína estimadas fora deste intervalo devem ser observadas com cautela. Com base nisso, as exigências líquidas são apresentadas para ganho de $250 \mathrm{~g}$.

Na Tabela 5, são apresentadas as estimativas de exigências líquidas de energia e proteína para ganho em PCV e na Tabela 6, as estimativas de exigências líquidas de energia e proteína e de proteína metabolizábel, para ganho em PV.

Os resultados encontrados para exigências líquidas de energia variaram de 544,44 a 892,21 kcal/250 g de ganho de corpo vazio, para cordeiros com pesos de 10 a $30 \mathrm{~kg}$, respectivamente. Estes valores são semelhantes aos do ARC (1980), que, para o mesmo ganho e pesos, são de 483,99 e 973,94 kcal. Os pesos de 25 e $30 \mathrm{~kg}$ de PCV foram inferiores aos de RATTRAY et al. (1973), que encontraram valores de 900 a $1035 \mathrm{kcal} / 250 \mathrm{~g}$, respectivamente.

As exigências líquidas de energia para ganho, verificadas neste trabalho, variaram de 522,05 a $825,27 \mathrm{kcal} / 250 \mathrm{~g}$ de ganho de PV, sendo semelhantes às divulgadas pelo NRC (1985) para cordeiros pesando 10 e $30 \mathrm{~kg}$ de PV. Segundo este comitê, os valores variam de 388 a $884 \mathrm{kcal} / 250 \mathrm{~g}$, respectivamente. Os resultados do presente trabalho são superiores (em média 20,65\%) aos calculados pela metodologia do AFRC (1993), que recomenda valores de 253,94 a $776,77 \mathrm{kcal} / 250 \mathrm{~g}$ de ganho, para cordeiros com 5 a $30 \mathrm{~kg}$ de PV. Entretanto, os valores de exigências de energia líquida para ganho em PV e PCV foram inferiores as encontradas por CARVALHO (1998), que variaram de 408 a $1021 \mathrm{kcal} / 250 \mathrm{~g}$ de ganho em PV e de 513 a 1390 kcal/250 g para ganho em PCV, para cordeiros com pesos de 5 a 30 $\mathrm{kg}$.

Os resultados obtidos para exigências líquidas de proteína, tanto para ganho de PCV como para ganho em PV, aumentaram com a elevação do peso.

Os valores variaram de 40,98 a 53,70 g/250 g de ganho em PCV e de 40,13 a 51,52 g/250 g de ganho em PV, para cordeiros de 5 e $30 \mathrm{~kg}$, respectivamente. Os resultados são semelhante aos apresentados pelo ARC (1980), o qual preconiza que a exigência de proteína é de $40 \mathrm{~g} / 200 \mathrm{~g}$ de ganho de $\mathrm{PV}$, para cordeiros com 20 e $30 \mathrm{~kg}$ de PV. Entretanto, discordam dos resultados preconizados pelo NRC (1985), que indicam valores de 55,44 e 42,74 g/250 g de ganho de PV para animais com 5 e $30 \mathrm{~kg}$ PV, respectivamente, e dos recomendados pelo AFRC (1993), que são de 23,10 e 17,15 g/150 g de ganho de PV, para cordeiros com os mesmos pesos anteriormente mencionados. A superioridade em termos dos valores em si pode estar relacionada ao grupo genético trabalhado, o qual estava constituído de animais 3/4 Texel. O aumento das exigências líquidas de proteína, do nascimento ao abate, pode estar relacionado ao fato de que até essa idade o crescimento muscular se encontrava em ritmo crescente. Provavelmente, se os animais tivessem sido abatidos com pesos superiores, seria possível verificar, então, decréscimo nas exigências líquidas de proteína.

CARVALHO (1998) também encontrou valores crescentes de exigências protéicas, à medida que o peso dos animais aumentou. Para PCV de 5 e $30 \mathrm{~kg}$, esse encontrou resultados de 39,91 e 44,99 g/250 g de ganho e, para os pesos vivo de 5 e $30 \mathrm{~kg}$, resultados de 32,27 e $36,04 \mathrm{~g} / 250 \mathrm{~g}$ de ganho. Esses valores foram, em média, $17,12 \%$ inferiores aos determinados no presente estudo.

Com caprinos, também foram observados aumentos nas exigências líquidas de proteína com a 
Rev. bras. zootec.

Tabela 5 - Estimativas das exigências líquidas de energia e proteína para $250 \mathrm{~g}$ de ganho, em função do peso de corpo vazio (PCV)

Table 5 - Estimates of energy and protein net requirements for $250 \mathrm{~g}$ of gain em the empty body weight $(E B W)$

\begin{tabular}{lcccccc}
\hline Item & \multicolumn{7}{c}{$\begin{array}{c}\text { PCV }(\mathrm{kg}) \\
\text { EBW }\end{array}$} \\
\cline { 2 - 7 } & 5 & 10 & 15 & 20 & 25 & 30 \\
\cline { 2 - 7 } & 399,93 & 544,44 & 653,00 & 743,20 & 821,79 & 892,21 \\
$\begin{array}{l}\text { Energia líquida } \\
\text { (kcal/anim.dia) }\end{array}$ & & & & & & \\
$\begin{array}{l}\text { Net energy (kcal/anim.day) } \\
\begin{array}{l}\text { Proteína líquida } \\
\text { (g/anim.dia) }\end{array}\end{array}$ & 40,98 & 45,57 & 48,34 & 50,49 & 52,23 & 53,70 \\
Net protein(g/anim.day) & & & & & & \\
\hline
\end{tabular}

Tabela 6 - Estimativas das exigências líquidas de energia e proteína e de proteína metabolizável para $250 \mathrm{~g}$ de ganho, em função do peso vivo (PV)

Table 6 - Estimates of net requirements of energy and protein and of metabolizable protein for 250 $g$ of gain, on the live weight (LW)

\begin{tabular}{lcccccc}
\hline Item & \multicolumn{5}{c}{ PV $(\mathrm{kg})$} \\
& \multicolumn{7}{c}{ LW } \\
\cline { 2 - 7 } & 5 & 10 & 15 & 20 & 25 & 30 \\
\hline $\begin{array}{l}\text { Energia líquida } \\
\text { (kcal/anim.dia) }\end{array}$ & 393,20 & 522,05 & 618,95 & 698,81 & 767,18 & 825,27 \\
$\begin{array}{l}\text { Net energy (kcal/anim.day) } \\
\begin{array}{l}\text { Proteína líquida } \\
\text { (g/animal/dia) }\end{array}\end{array}$ & 40,13 & 44,15 & 46,76 & 48,71 & 50,27 & 51,52 \\
$\begin{array}{l}\text { Net protein (g/anim.day) } \\
\text { Proteína metabolizável } \\
\text { (g/anim.dia) }\end{array}$ & 79,09 & 91,49 & 100,72 & 108,41 & 115,15 & 121,13 \\
$\begin{array}{l}\text { Metabolizable protein } \\
\text { (g/anim.day) }\end{array}$ & & & & & & \\
\hline
\end{tabular}

elevação do peso. RESENDE (1989) observou resultados de 29,68 a $34,71 \mathrm{~g} / 150 \mathrm{~g}$ de ganho para caprinos de 5 a $15 \mathrm{~kg}$ de PV. SOUSA (1998 b) verificou valores de 25,24 a 27,48 g/150 g de ganho, para caprinos de 18 a $26 \mathrm{~kg}$ de PV.

Os resultados obtidos para proteína metabolizável para ganho (exigências dietéticas), apresentados na Tabela 6, são semelhantes aos apresentados pelo AFRC (1993), que preconizam valores de 110 e $114 \mathrm{~g} / 250 \mathrm{~g}$ de ganho, para animais de 20 e $30 \mathrm{~kg}$ de PV, respectivamente. Entretanto, os valores são, em média, 20\% superiores aos verificados por CARVALHO (1998), que encontrou resultados de $65,11 \mathrm{~g} / 250 \mathrm{~g}$ de ganho, para cordeiros com $5 \mathrm{~kg}$ de $\mathrm{PV}$ e de $93,58 \mathrm{~g} / 250 \mathrm{~g}$ de ganho, para animais com $30 \mathrm{~kg}$ PV.

\section{Conclusões}

Em cordeiros 3/4 Texel + 1/4 Ideal, os conteúdos corporais de proteína bruta, extrato etéreo e energia bruta aumentaram com a elevação do PCV de 5 para
$30 \mathrm{~kg}$, e o conteúdo de matéria mineral aumentou dos 5 aos $20 \mathrm{~kg}$, mantendo-se constante deste peso até os $30 \mathrm{~kg}$ PV.

A exigência líquida de energia, para cordeiros com $20 \mathrm{~kg}$ de peso vivo e ganho de peso diário de $0,250 \mathrm{~kg}$, é semelhante ao valor recomendado pelo NRC e superior ao indicado pelo AFRC (1993). Para a exigência líquida de proteína, o valor determinado é próximo do preconizado pelo NRC (1985), encontrando-se acima do recomendado pelo AFRC (1993).

\section{Referências Bibliográficas}

AGRICULTURAL RESEARCH COUNCIL - ARC. 1980. The nutrient requirements of ruminant livestock. London: Commonwealth Agricultural Bureaux. 351p.

AGRICULTURAL AND FOOD RESEARCH COUNCIL AFRC. 1993. Energy and protein requirements of ruminants. An advisory manual prepared by the AFRCT Technical Committee on responses to nutrients. CAB International, Wallingford, UK. 151p.

ARMSTRONG, D. G. Determination of the energy and protein 
requirements for milk and beef production - the AFRC system. In: SIMPÓSIO INTERNACIONAL SOBRE EXIGÊNCIAS NUTRICIONAIS DE RUMINANTES, 1995, Viçosa. Anais... Viçosa: Universidade Federal de Viçosa, 1995, p.7-52.

CARVALHO, S. Desempenho, composição corporal e exigências nutricionais de cordeiros machos inteiros, machos castrados e fêmeas alimentados em confinamento: Santa Maria, RS: UFSM, 1998. 100p. Dissertação (Mestrado em Zootecnia) - Universidade Federal de Santa Maria, 1998.

KOCK, S.W., PRESTON, R.L. 1979. Estimation of bovine carcass composition by the urea dilution technique. J. Anim. Sci., 48(2):319-327.

NATIONAL RESEARCH COUNCIL - NRC. 1985. Nutrient requirements of sheep. 6.ed. Washington: National Academy Press. 99p.

RATTRAY, P.V., GARRET, W.N., MEYER, H.H. et al. 1973. Net energy requirements for growth of lambs age three to five months. J. Anim. Sci., 37(6):1386-1389.

RESENDE, K.T. Métodos de estimativa da composição corporal $e$ exigências nutricionais de proteína, energia $e$ macroelementos inorgânicos de caprinos em crescimento: Viçosa, MG: UFV, 1989. 128p. Tese (Doutorado em Zootecnia) - Universidade Federal de Viçosa, 1989.

SAMPELAYO, M.R.S., LARA, L., PRIETO, I. et al. 1993. Composicion corporal y utilizacion de la energia del cabrito y cordero lactante. Invest. Agr. Prod. Sanid. Anim., 8(1):5-15.
SAS INSTITUTE. 1990. SAS User's guide: statistics, Cary/ North Carolina, v.2, version 6, 4.ed. 846p.

SEARLE, T.W., GRAHAM, N. McC., SMITH, E. 1979. Studies of weaned lams before, during and after a period of weight loss. II. Body composition. Aust. J. Agric. Res., 30:525-531.

SILVA, D.J. 1990. Análise de alimentos (métodos químicos e biológicos). Viçosa: Imprensa Universitária. 165p.

SOUSA, H.M.H., QUEIROZ, A.C., RESENDE, K.T. 1998 a. Exigências nutricionais de caprinos da raça Alpina em crescimento. 2. Composição corporal e do ganho em peso em proteína, extrato etéreo, energia, cálcio e fósforo. $R$. Bras. Zootec., 27(1):193-197.

SOUSA, H.M.H., QUEIROZ, A.C., RESENDE, K.T. et al. 1998b. Exigências nutricionais de caprinos da raça Alpina em crescimento. 3. Exigências nutricionais de energia, proteína, cálcio e fósforo. R. Bras. Zootec., 27(1):198-202.

WILKINSON, R.G., GREENHALGH, J.F.D. 1995. Growth of lambs offered fixed amounts of roughage and concentrate either simultaneously, progressively or separately. J. Agric. Sci., 124:301-311.

Recebido em: 12/05/99

Aceito em: 18/10/99 